\title{
Exosomal circ-BRWD1 contributes to osteoarthritis development through the modulation of miR-1277/TRAF6 axis
}

\author{
Zhenye Guo ${ }^{1}$, Huan Wang ${ }^{1}$, Feng Zhao ${ }^{1}$, Min Liu', Feida Wang ${ }^{1}$, Mingming Kang ${ }^{2}$, Weifu He${ }^{2}$ and Zhi Lv ${ }^{1 *}$
}

\begin{abstract}
Background: Circular RNAs (circRNAs) can act as vital players in osteoarthritis (OA). However, the roles of circRNAs in OA remain obscure. Herein, we explored the roles of exosomal circRNA bromodomain and WD repeat domain containing 1(circ-BRWD1) in OA pathology.

Methods: In vitro model of OA was constructed by treating CHON-001 cells with interleukin-1 $\beta$ (IL-1 $\beta)$. Quantitative real-time polymerase chain reaction (qRT-PCR) assay was used for circ-BRWD1, BRWD, miR-1277, and TNF receptorassociated factor 6 (TRAF6) levels. RNase R assay was conducted for the feature of circ-BRWD1. Transmission electron microscopy (TEM) was employed to analyze the morphology of exosomes. Western blot assay was performed for protein levels. Cell Counting Kit-8 (CCK-8) assay, flow cytometry analysis, and 5-Ethynyl-2'deoxyuridine (EDU) assay were adopted for cell viability, apoptosis, and proliferation, respectively. Enzyme-linked immunosorbent assay (ELISA) was carried out for the concentrations of interleukin-6 (IL-6) and interleukin-8 (IL-8). Dual-luciferase reporter and RNA immunoprecipitation (RIP) assays were used to analyze the interaction between miR-1277 and circ-BRWD1 or TRAF6.
\end{abstract}

Results: Circ-BRWD1 was increased in OA cartilage tissues, IL-1 $\beta$-treated $\mathrm{CHON}-001$ cells, and the exosomes derived from IL-1 $\beta$-treated CHON-001 cells. Exosome treatment elevated circ-BRWD1 level, while exosome blocker reduced circ-BRWD1 level in IL-1 $\beta$-treated CHON-001 cells. Silencing of circ-BRWD1 promoted cell viability and proliferation and repressed apoptosis, inflammation, and extracellular matrix (ECM) degradation in IL-1 $\beta$-stimulated CHON-001 cells. For mechanism analysis, circ-BRWD1 could serve as the sponge for miR-1277 to positively regulate TRAF6 expression. Moreover, miR-1277 inhibition ameliorated the effects of circ-BRWD1 knockdown on IL-1 $\beta$-mediated CHON-001 cell damage. Additionally, miR-1277 overexpression relieved IL-1 $\beta$-induced CHON-001 cell injury, while TRAF6 elevation restored the impact.

Conclusion: Exosomal circ-BRWD1 promoted IL-1ß-induced CHON-001 cell progression by regulating miR-1277/ TRAF6 axis.

Keywords: OA, Exosome, Circ-BRWD1, MiR-1277, TRAF6

\footnotetext{
* Correspondence: Ivzhi2020@tom.com

'Department of Orthopaedics, Second Hospital of Shanxi Medical University, No.2 Hospital, Shanxi Medical University, 382 Wuyi Road, Xinghualing District, Taiyuan City, Shanxi Province, China

Full list of author information is available at the end of the article
}

\section{$\triangle B M C$}

(c) The Author(s). 2021 Open Access This article is licensed under a Creative Commons Attribution 4.0 International License, which permits use, sharing, adaptation, distribution and reproduction in any medium or format, as long as you give appropriate credit to the original author(s) and the source, provide a link to the Creative Commons licence, and indicate if changes were made. The images or other third party material in this article are included in the article's Creative Commons licence, unless indicated otherwise in a credit line to the material. If material is not included in the article's Creative Commons licence and your intended use is not permitted by statutory regulation or exceeds the permitted use, you will need to obtain permission directly from the copyright holder. To view a copy of this licence, visit http://creativecommons.org/licenses/by/4.0/ The Creative Commons Public Domain Dedication waiver (http://creativecommons.org/publicdomain/zero/1.0/) applies to the data made available in this article, unless otherwise stated in a credit line to the data. 


\section{Highlights}

1. Circ-BRWD1 is upregulated in osteoarthritis patients and IL-1 $\beta$-induced chondrocyte cell line.

2. Exosomal circ-BRWD1 is upregulated in IL-1 $\beta$ induced chondrocyte cell line.

3. Circ-BRWD1 knockdown promotes IL-1 $\beta$-mediated chondrocyte cell viability and inhibits apoptosis, inflammation, and ECM degradation.

4. Circ-BRWD1 knockdown ameliorates IL-1 $\beta$ mediated chondrocyte injury by regulating miR1277/TRAF6 axis.

\section{Introduction}

Osteoarthritis (OA) is a slow-developing degenerative joint disease with a high incidence, which is related to age, obesity, tension, strain, trauma, joint deformities, and other factors $[1,2]$. OA is characterized by structural change of subchondral bone, inflammation of synovitis, and destruction of cartilage matrix [3, 4]. At present, methods such as anti-inflammatory analgesics and artificial joint replacement surgery are mainly used to reduce OA patient's joint pain and control its progress; however, the side effects and high costs hinder their wide application $[5,6]$. Thus, identifying novel treatment strategies for OA is very necessary.

Circular RNAs (circRNAs) are a sort of non-coding RNAs (ncRNAs) with closed-loop structures, which can regulate gene expression by competitive targeting microRNAs (miRNAs) [7, 8]. Emerging evidence has reported that circRNAs function as critical regulators in multiple human diseases, including OA. For example, circ 00050105 facilitated ECM degradation and inflammatory response in interleukin-1 $\beta$ (IL-1 $\beta$ )-treated chondrocytes by sponging miR-26a [9]. Circ_0045714 accelerated chondrocyte proliferation and ECM synthesis and restrained apoptosis by modulating miR-193b and IGF1R [10]. As for circ-BRWD1 (circ_0116061), the heatmap showed it was upregulated in OA cartilage tissues compared to normal cartilage tissues [11]. However, whether the abnormal expression of circ-BRWD1 (circ_0116061) plays a role in OA is still undefined. Exosomes are tiny particles with a diameter of $30-150 \mathrm{~nm}$ which can be released by multiple cell types [12]. It has been documented that circRNAs are abundant in exosomes and can be transferred into other cells to regulate biological functions [13]. In this study, the functions of exosomemediated circ-BRWD1 in OA were investigated.

As a class of small ncRNAs, miRNAs participate in regulating multiple biological processes via recognization of the 3' untranslated region (3'UTR) of target mRNAs [14]. In OA, miR-34a overexpression facilitated the apoptosis and suppressed the proliferation of chondrocytes in the pathophysiological process of $\mathrm{OA}$ via targeting SIRT1/p53 signaling pathway [15]. MiR-101 inhibition reversed IL-1 $\beta$-activation ECM degradation in chondrocytes through targeting Sox9 [16]. Moreover, Wang et al. disclosed that miR-1277 alleviated ECM degradation in IL-1 $\beta$-treated articular chondrocytes via interacting with MMP13 and ADAMTS5 [17]. These findings indicated the vital role of miR-1277 in OA. TNF receptor-associated factor 6 (TRAF6) has been demonstrated to be targeted by miR-146a to regulate OA chondrocyte proliferation and apoptosis [18]. By analyzing bioinformatics software circinteractome and Targetscan, miR-1277 was found to contain the binding sites of circ-BRWD1 and TRAF6, but the relationships among circ-BRWD1, miR-1277, and TRAF6 in OA development are still unclear.

The present study aimed to determine the expression profiles of exosomal circ-BRWD1, miR-1277, and TRAF6 in IL-1 $\beta$-activated chondrocytes and further explore their functional roles in OA development.

\section{Materials and methods}

\section{Tissues acquisition}

The OA cartilage tissue specimens were harvested from 32 OA patients undergoing total knee arthroplasty and the normal cartilage tissue specimens were harvested from 32 traumatic amputees at the Second Hospital of Shanxi Medical University. The specimens were preserved at $-80^{\circ} \mathrm{C}$ until further experiments. The work was approved by the Ethics Committee of Second Hospital of Shanxi Medical University. Written informed consents were provided by all patients.

\section{Cell culture and IL-1 $\beta$ treatment}

The chondrocyte cell line $\mathrm{CHON}-001$ was acquired from the American Type Culture Collection (ATCC, Manassas, VA, USA) and maintained in Dulbecco's modified Eagle's medium (DMEM; Sigma-Aldrich, St. Louis, MO, USA) added with $10 \%$ fetal bovine serum (FBS; SigmaAldrich) and $1 \%$ penicillin-streptomycin (Sigma-Aldrich) in a humid incubator with $5 \% \mathrm{CO}_{2}$ at $37^{\circ} \mathrm{C}$.

To stimulate OA chondrocyte model, CHON-001 cells were exposed to IL-1 $\beta(5 \mathrm{ng} / \mathrm{mL}, 10 \mathrm{ng} / \mathrm{mL}$, and $20 \mathrm{ng} /$ $\mathrm{mL}$; Sigma-Aldrich) at $37^{\circ} \mathrm{C}$ for $24 \mathrm{~h}$. The untreated cells $(0 \mathrm{ng} / \mathrm{mL})$ were used as controls. $10 \mathrm{ng} / \mathrm{mL} \mathrm{IL}-1 \beta$-treated cells were chosen for further experiments.

\section{Quantitative real-time polymerase chain reaction (qRT- PCR)}

The RNA extraction was conducted through the usage of TRIzol reagent (Beyotime, Shanghai, China). RNA treatment was performed on total RNA with $3 \mathrm{U} / \mu \mathrm{g}$ RNase R (Epicenter Biotechnologies, Madison, WI, USA) for $15 \mathrm{~min}$ at $37^{\circ} \mathrm{C}$. Then the M-MLV Reverse Transcriptase Kit (Promega, Madison, WI, USA) or TaqMan 
MicroRNA Reverse Transcription Kit (Applied Biosystems, Foster City, CA, USA) was adopted for the reverse transcription of RNA samples. QRT-PCR analysis was manipulated with BeyoFast ${ }^{\mathrm{Tm}}$ SYBR Green qPCR Mix (Beyotime) and indicated primers (GeneCopoeia, Guangzhou, China). The primers were circ-BRWD1: (F: 5'-AGCACGGATTTGGAGATTTG-3' and R: 5'CGTAGCAAAGACTGCCTTCC-3'); BRWD1: (F: 5' CCAGCGCATCGGTCCTATG-3' and R: 5'-CTTCCT GCACCAAGTAAAGAAGT-3'); miR-1277: (F: 5' ACACTCCAGCTGGGAAATATATATATATATGT-3' and R: 5' -TGGTGTCGTGGAGTCG-3'); TRAF6: (F: $5^{\prime}$ TGTTGCAGCAGCTATTTTGC-3' and R: 5'-CTTC TCGAGGGCACTAGCAC-3'); GAPDH: (F: 5' GGAAGGTGAAGGTCGGAGTC-3' and R: 5'-CGTT CTCAGCCTTGACGGT-3'); U6: (F: 5'-GCTCGCTTCG GCAGCACATA-3' and R: 5'-ACGCTTCACGAATT TGCGT-3'). The expression was estimated via the $2^{-\Delta \Delta C t}$ strategy with GAPDH or U6 as a negative control.

\section{Subcellular fraction assay}

The isolation of nuclear and cytoplasmic fractions was conducted with the PARIS Kit (Life Technologies, Grand Island, NY, USA) in line with the protocols of the manufacturers. The RNAs isolated from the fractions of CHON-001 cells were subjected to the aforementioned qRT-PCR analysis for circ-BRWD1, U6 (a control for nuclear fraction) and GAPDH (a control for cytoplasmic fraction) levels.

\section{Isolation of exosomes}

The ExoQuick precipitation kit (System Biosciences, Mountain View, CA, USA) was used to isolate exosomes from the culture media of CHON-001 cells. Briefly, the media were collected and centrifuged at $1000 \times g$ for 10 min to sediment the cells. Then, the media were centrifuged at $10,000 \times g$ for $30 \mathrm{~min}$ to remove the dead cells and cellular debris. After that, the ExoQuick solution was supplemented into the supernatant for $30 \mathrm{~min}$ at $4{ }^{\circ} \mathrm{C}$ and then centrifuged for $40 \mathrm{~min}$ at $2000 \times g$. Subsequently, the supernatant was removed and the exosomecontaining pellet was washed with PBS (Beyotime) and then resuspended in PBS (Beyotime).

\section{Transmission electron microscopy (TEM)}

The exosomal morphology was analyzed by TEM (JEOL Ltd., Tokyo, Japan) using negative staining according to the previous report [19]. The images were observed using the FEI TecnaiG2 spirit transmission electron microscope (Thermo-Fischer, Waltham, MA, USA) operated at $80 \mathrm{kV}$.

\section{Western blot assay}

The extraction of total protein was done utilizing RIPA buffer (Beyotime) and quantified utilizing the BCA protein assay kit (Tiangen, Beijing, China). An equal amount of protein was resolved with sodium dodecyl sulfonate-polyacrylamide gel (Solarbio, Beijing, China) and then transferred onto polyvinylidene difluoride membranes (Sigma-Aldrich). After blocking in 5\% defatted milk for $1 \mathrm{~h}$ at indoor temperature, the membranes were incubated with primary antibodies against CD9 (ab223052; Abcam, Cambridge, MA, USA), CD63 (ab68418; Abcam), CyclinD1 (ab226977; Abcam), Bax (ab104156; Abcam), matrix metalloprotein 13 (MMP13; ab39012; Abcam), aggrecan (ab36861; Abcam), TRAF6 (ab137452; Abcam) or GAPDH (ab37168; Abcam) overnight at $4{ }^{\circ} \mathrm{C}$ and indicated secondary antibody (ab6789; Abcam) for $1.5 \mathrm{~h}$ at indoor temperature. The ECL kit (Beyotime) was employed for chemiluminescence imaging.

\section{Exosomes or GW4869 treatment}

CHON-001 cells were plated into 6 -well plates $\left(1 \times 10^{5}\right.$ cells/well) and then the exosomes $(20 \mu \mathrm{g})$ derived from $10 \mathrm{ng} / \mathrm{mL}$ IL-1 $\beta$-triggered CHON-001 cells were added into the culture media for $48 \mathrm{~h}$. The control media were treated with PBS (Beyotime).

To block exosome secretion, IL-1 $\beta$-treated CHON-001 cells were treated with $20 \mu \mathrm{M}$ GW4869 (Sigma-Aldrich) for $2 \mathrm{~h}$ prior to IL-1 $\beta$ (Sigma-Aldrich) exposure. After $48 \mathrm{~h}$, the supernatants were harvested for circ-BRWD1 expression via qRT-PCR analysis.

\section{Cell transfection}

Circ-BRWD1 short interfering RNA (si-circ-BRWD1) and scramble control (si-NC), the overexpression vector of circ-BRWD1 (circ-BRWD1) and its control (pCD5ciR), miR-1277 mimics (miR-1277) and control mimics (miR-NC), miR-1277 inhibitors (anti-miR-1277) and anti-miR-NC, the overexpression vector of TRAF6 (TRAF6) and pcDNA were purchased from GeneCopoeia. CHON-001 cells $\left(1 \times 10^{4}\right.$ cells/well $)$ were seeded into 24-well plates and the oligonucleotides $(50 \mathrm{nM})$ or vectors $(2 \mu \mathrm{g})$ were transfected into $\mathrm{CHON}-001$ cells utilizing Lipofectamine 2000 (Invitrogen, Carlsbad, CA, USA) according to the manufacturers' instructions.

\section{Cell Counting Kit-8 (CCK-8) assay}

Following relevant treatment, $\mathrm{CHON}-001$ cell viability was tested by CCK- 8 assay. In brief, $\mathrm{CHON}-001$ cells were plated into 96-well plates $\left(1 \times 10^{4}\right.$ cells/well $)$ and then cultivated for $72 \mathrm{~h} .20 \mu \mathrm{L}$ CCK-8 (Sigma-Aldrich) was treated into each well for further $3 \mathrm{~h}$. After that, the OD value was measured at $450 \mathrm{~nm}$ with a microplate reader (BioTek, Winooski, VT, USA). 


\section{Flow cytometry analysis}

CHON-001 cell apoptosis was assessed with Annexin Vfluorescein isothiocyanate (FITC)/propidium iodide (PI) Apoptosis Detection Kit (Beyotime) according to the manufacturers' guidelines. Briefly, $\mathrm{CHON}-001$ cells were collected and rinsed with PBS (Beyotime) after relevant treatment and then resuspended in binding buffer. After that, $5 \mu \mathrm{L}$ AnnexinV-FITC and $5 \mu \mathrm{L}$ PI were added and maintained for $15 \mathrm{~min}$ in the dark. At last, cell apoptosis was examined with a FACScan ${ }^{\circ}$ flow cytometry (BD Biosciences, San Jose, CA, USA).

\section{5-Ethynyl-2'-deoxyuridine (EDU) assay}

EDU assay was conducted to evaluate cell viability through the usage of EDU assay kit (Solarbio, Beijing, China). In short, the treated CHON-001 cells were seeded into 12-well plates and incubated with EDU buffer for $2 \mathrm{~h}$ at $37^{\circ} \mathrm{C}$. Then the cells were fixed with $4 \%$ formaldehyde for $30 \mathrm{~min}$, permeabilizated for $20 \mathrm{~min}$ using $0.1 \%$ Triton X-100. Thereafter, the cells were exposed to EDU solution for $30 \mathrm{~min}$ and then stained cell nuclei using $5 \mu \mathrm{g} / \mathrm{mL}$ Hoechst 33342 for $20 \mathrm{~min}$. The images were captured with a fluorescence microscope (Olympus, Tokyo, Japan) and the EDU-positive cells were counted.

\section{Enzyme-linked immunosorbent assay (ELISA)}

The concentrations of interleukin-6 (IL-6) and interleukin-8 (IL-8) were conducted utilizing Human IL6 ELISA Kit (ab178013; Abcam) and Human IL-8 ELISA Kit (ab214030; Abcam) according to the manufacturers' instructions.

\section{Dual-luciferase reporter assay}

The regions of circ-BRWD1 (or TRAF6 3'UTR) including or lacking the predicted miR-1277 binding sequences were amplified and inserted into pmirGLO vector (Promega), generating WT-circ-BRWD1, MUT-circBRWD1, TRAF6 3'UTR-WT, and TRAF6 3'UTR-MUT. The generation of WT-circ-BRWD1, MUT-circBRWD1, TRAF6 3'UTR-WT, and TRAF6 3'UTR-MUT was accomplished by GeneCopoeia. Then the generated vectors were transfected into $\mathrm{CHON}-001$ cells in combination with miR-1277 or miR-NC. After the posttransfection for $48 \mathrm{~h}$, dual-luciferase assay kit (Promega) was adopted for renilla and firefly luciferase activities.

\section{RNA immunoprecipitation (RIP) assay}

The Magna RIP ${ }^{\mathrm{TM}}$ RNA Binding Protein Immunoprecipitation Kit (Millipore, Bedford, MA, USA) was adopted for RIP assay. CHON-001 cells were lysed in RIP buffer and then incubated overnight with beads coated with antibody immunoglobulin G (IgG) or argonaute-2 (anti-Ago2) at $4{ }^{\circ} \mathrm{C}$. Then the RNAs on the beads were retrieved for circ-BRWD1, miR-1277, and TRAF6 levels via qRT-PCR assay.

\section{Statistical analysis}

The experiments were carried out in triple times. The collected data were analyzed by GraphPad Prism 7 software and presented as mean \pm standard deviation. The linear correlation between the levels of miR-1277 and circ-BRWD1 or TRAF6 was estimated by Pearson's correlation coefficient analysis. The differences between two groups were estimated by Student's $t$ test, while those among three groups were estimated by one-way analysis of variance (ANOVA). The differences were defined as significant when $P<0.05$.

\section{Results}

Circ-BRWD1 was upregulated in OA cartilage tissues and IL-1 $\beta$-induced CHON-001 cells

At the beginning, qRT-PCR assay was conducted to detect the expression level of circ-BRWD1 in OA cartilage specimens and normal cartilage specimens. The results showed that circ-BRWD1 level was markedly increased in OA cartilage specimens compared to normal controls (Fig. 1A). Then we examined the level of circ-BRWD1 in IL-1 $\beta$-stimulated CHON-001 cells and found that circBRWD1 level was enhanced in IL-1 $\beta$-induced $\mathrm{CHON}$ 001 cells in a dose-dependent way (Fig. 1B). As demonstrated by subcellular fraction assay, circ-BRWD1 was mainly enriched in the cytoplasm of CHON-001 cells (Fig. 1C). Moreover, our results exhibited that circBRWD1 was resistant to RNase R treatment, while linear BRWD1 was digested by RNase R (Fig. 1D). These findings suggested that circ-BRWD1 might play a role in OA progression.

\section{Exosomal circ-BRWD1 level was elevated in IL-1 $\beta$-induced CHON-001 cells}

Subsequently, the exosomes were isolated from $\mathrm{CHON}$ 001 cells and IL-1 $\beta$-treated CHON-001 cells. The morphology of the isolated exosomes was observed by TEM. The results indicated that the particles showed a round or oval membrane (Fig. 2A). Furthermore, we found that exosomal markers (CD9 and CD63) were highly expressed in the particles derived from $\mathrm{CHON}$ 001 cells and IL-1 $\beta$-treated CHON-001 cells, as measured by western blot assay (Fig. 2B). These findings indicated that the isolated particles were exosomes. Next, the level of circ-BRWD1 in the exosomes derived from IL-1 $\beta$-treated $\mathrm{CHON}-001$ cells was examined by qRT-PCR assay, exhibiting that exosomal circ-BRWD1 level was elevated in IL-1 $\beta$-treated $\mathrm{CHON}-001$ cells dose-dependently (Fig. 2C). We then added the exosomes derived from IL-1 $\beta$-treated $\mathrm{CHON}-001$ cells into CHON-001 cells for $48 \mathrm{~h}$ and found the expression level 
A

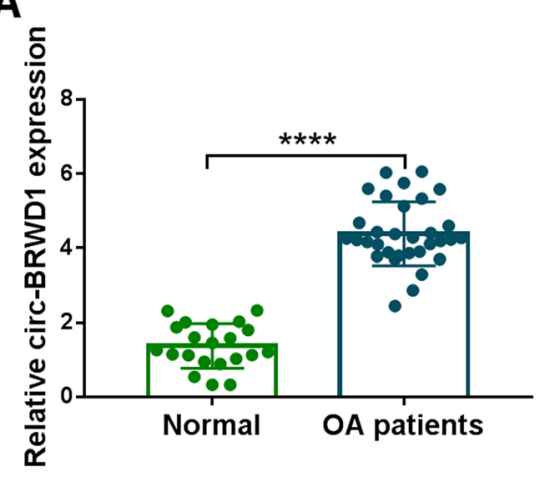

C

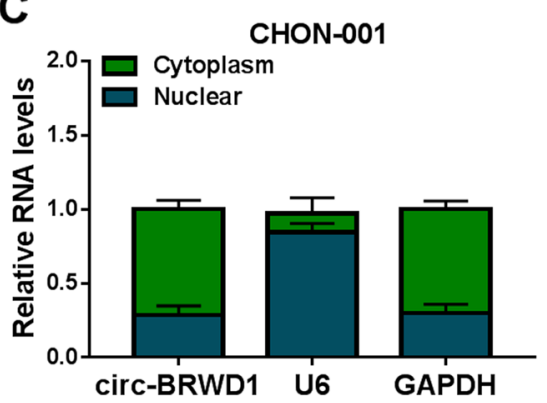

B

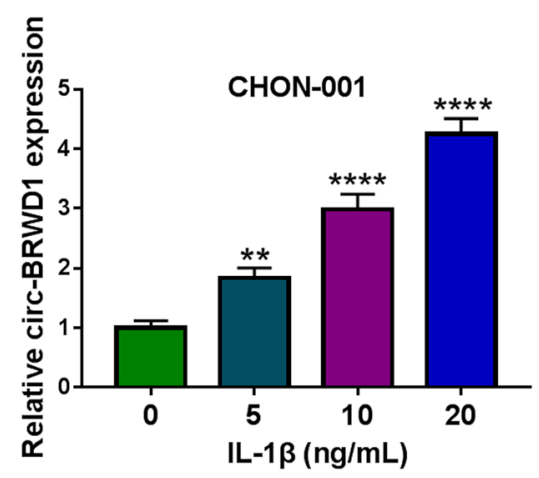

D

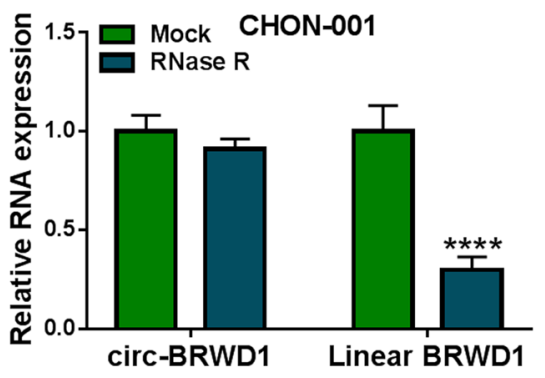

Fig. 1 High level of circ-BRWD1 in OA cartilage tissues and IL-1 $\beta$-induced CHON-001 cells. A QRT-PCR assay was conducted for circ-BRWD1 level in OA and non-OA cartilage tissues. B QRT-PCR assay was employed to determine circ-BRWD1 level in different doses of IL-1 $\beta$-treated CHON-001 cells. C QRT-PCR assay was used for the expression of circ-BRWD1 in the nuclear and cytosolic fractions of CHON-001 cells. D QRT-PCR assay was used to determine the expression levels of circ-BRWD1 and linear BRWD1 in CHON-001 cells treated with or without RNase R. The expression of circ-BRWD1 and BRWD1 was examined by $2^{-\triangle \Delta C t}$ method with normalization to GAPDH. ${ }^{* *} P<0.001,{ }^{* * * P}<0.0001$

of circ-BRWD1 released from exosomes was increased in CHON-001 cells compared to control groups (Fig. 2D). In addition, GW4869 was used to inhibit the exosome release by IL- $1 \beta$-treated $\mathrm{CHON}-001$ cells. The results showed that GW4869 treatment decreased the level of circ-BRWD1 in IL-1 $\beta$-treated CHON-001 cells (Fig. 2E). All these results indicated that exosome mediated the transmission of circ-BRWD1 in IL-1 $\beta$-treated CHON-001 cells.

Circ-BRWD1 silencing reversed the effects on cell viability, apoptosis, inflammation, and ECM degradation in CHON001 cells mediated by IL- $1 \beta$

In order to investigate the functional roles of circBRWD1 in OA development, CHON-001 cells were transfected with si-circ-BRWD1 or si-NC and then treated with IL-1 $\beta$ for $24 \mathrm{~h}$. As exhibited in Fig. 3A, the upregulation of circ-BRWD1 in CHON-001 cells caused by IL-1 $\beta$ treatment was effectively overturned by the transfection of si-circ-BRWD1, indicating the successful transfection of si-circ-BRWD1. CCK-8 assay showed that IL-1 $\beta$ treatment led to an obvious inhibition in the viability of CHON-001 cells in a concentration-dependent manner (Fig. 3B). CCK-8 assay also exhibited that circBRWD1 silencing reversed the inhibitory effect of IL-1 $\beta$ on cell viability in CHON-001 cells (Fig. 3C). Flow cytometry analysis showed that IL- $1 \beta$ treatment apparently facilitated the apoptosis of CHON-001 cells, whereas circ-BRWD1 deficiency abrogated the impact (Fig. 3D). EDU assay indicated that IL-1 $\beta$ inhibited CHON-001 cell proliferation, while circ-BRWD1 silencing reversed the effect (Fig. 3E). IL-1 $\beta$ treatment reduced CyclinD1 level and increased Bax level in CHON-001 cells, while circ-BRWD1 deficiency reversed the effects (Fig. 3F). The results of ELISA showed that IL- $1 \beta$ exposure markedly increased the levels of IL- 6 and IL- 8 in CHON-001 cells, while the effects were ameliorated by circ-BRWD1 inhibition (Fig. 3G). In addition, western blot assay showed that IL-1 $\beta$ treatment increased MMP13 level and decreased aggrecan level in CHON-001 cells, with circ-BRWD1 knockdown reversing the impacts (Fig. $3 \mathrm{H}$ ). All these data suggested that circ-BRWD1 knockdown promoted IL-1 $\beta$-mediated cell viability and suppressed IL-1 $\beta$-mediated apoptosis, inflammation and ECM degradation in $\mathrm{CHON}-001$ cells.

\section{MiR-1277 functioned as the sponge for circ-BRWD1}

To explore the underlying mechanisms of circ-BRWD1 in OA development, we searched online website circinteractome and found that miR-1277 contained the 


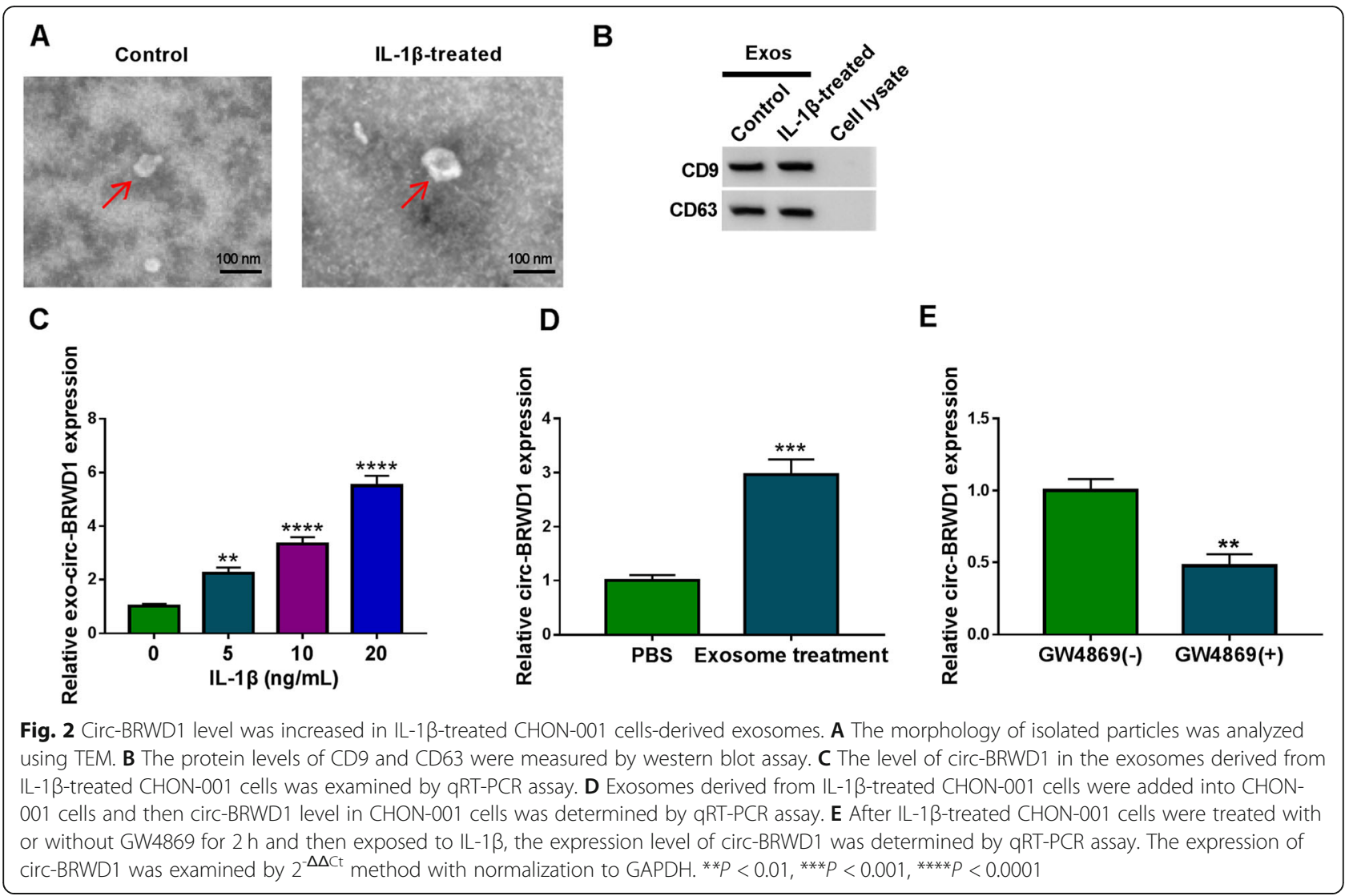

complementary sequences of circ-BRWD1 (Fig. 4A). Then dual-luciferase reporter assay and RIP assay were conducted to verify the interaction between circBRWD1 and miR-1277. As demonstrated by dualluciferase reporter assay, miR-1277 transfection strikingly suppressed the luciferase activity of WT-circBRWD1 in CHON-001 cells, but had no effect on the luciferase activity of MUT-circ-BRWD1 (Fig. 4B). RIP assay showed that the levels of miR-1277 and circBRWD1 immunoprecipitated with Ago2 were all enhanced compared to IgG control groups, further confirming the combination between circ-BRWD1 and miR1277 (Fig. 4C). Moreover, we found that miR-1277 level was reduced in OA cartilage tissues and different doses of IL-1 $\beta$-treated CHON-001 cells (Fig. 4D, E). As estimated by Pearson's correlation coefficient analysis, there was an inverse correlation between miR-1277 and circBRWD1 in OA cartilage tissues (Fig. 4F). In addition, the overexpression vector of circ-BRWD1 was successfully transfected in IL-1 $\beta$-treated CHON-001 cells, as demonstrated by the upregulation of circ-BRWD1 in IL$1 \beta$-treated CHON-001 cells after the transfection of circ-BRWD1 (Fig. 4G). We also demonstrated that circBRWD1 silencing markedly elevated the expression level of miR-1277 in IL-1 $\beta$-stimulated CHON-001 cells, while circ-BRWD1 overexpression presented the opposite results (Fig. 4H). Collectively, circ-BRWD1 negatively modulated miR-1277 expression via acting as the sponge for miR-1277.

Inhibition of miR-1277 abrogated the effects of circBRWD1 knockdown on cell viability, apoptosis, inflammation and ECM degradation in IL-1 $\beta$-treated CHON-001 cells

To further analyze the functions of circ-BRWD1/miR1277 axis in OA progression, $\mathrm{CHON}-001$ cells were divided into 6 groups: control, IL-1 $\beta, \mathrm{IL}-1 \beta+\mathrm{si}-\mathrm{NC}, \mathrm{IL}-1 \beta+$ si-circ-BRWD1, IL-1 $\beta+$ si-circ-BRWD1+anti-miR-NC and IL-1 $\beta+$ si-circ-BRWD1+anti-miR-1277. As shown in Fig. 5A, circ-BRWD1 knockdown significantly elevated miR-1277 level in IL-1 $\beta$-treated CHON-001 cells, while miR-1277 inhibition reversed the influence. The results of CCK-8 assay and flow cytometry analysis indicated that circ-BRWD1 silencing facilitated the viability and repressed the apoptosis of $\mathrm{CHON}-001$ cells mediated by IL-1 $\beta$ treatment, with miR-1277 suppression ameliorated the impacts (Fig. 5B-D). EDU assay showed that that circ-BRWD1 silencing aggravated the viability in IL-1 $\beta$ treated CHON-001 cells, while miR-1277 inhibition overturned the impact (Fig. 5E). Circ-BRWD1 knockdown upregulated CyclinD1 protein level and downregulated Bax protein level in IL- $1 \beta$-stimulated $\mathrm{CHON}-001$ 

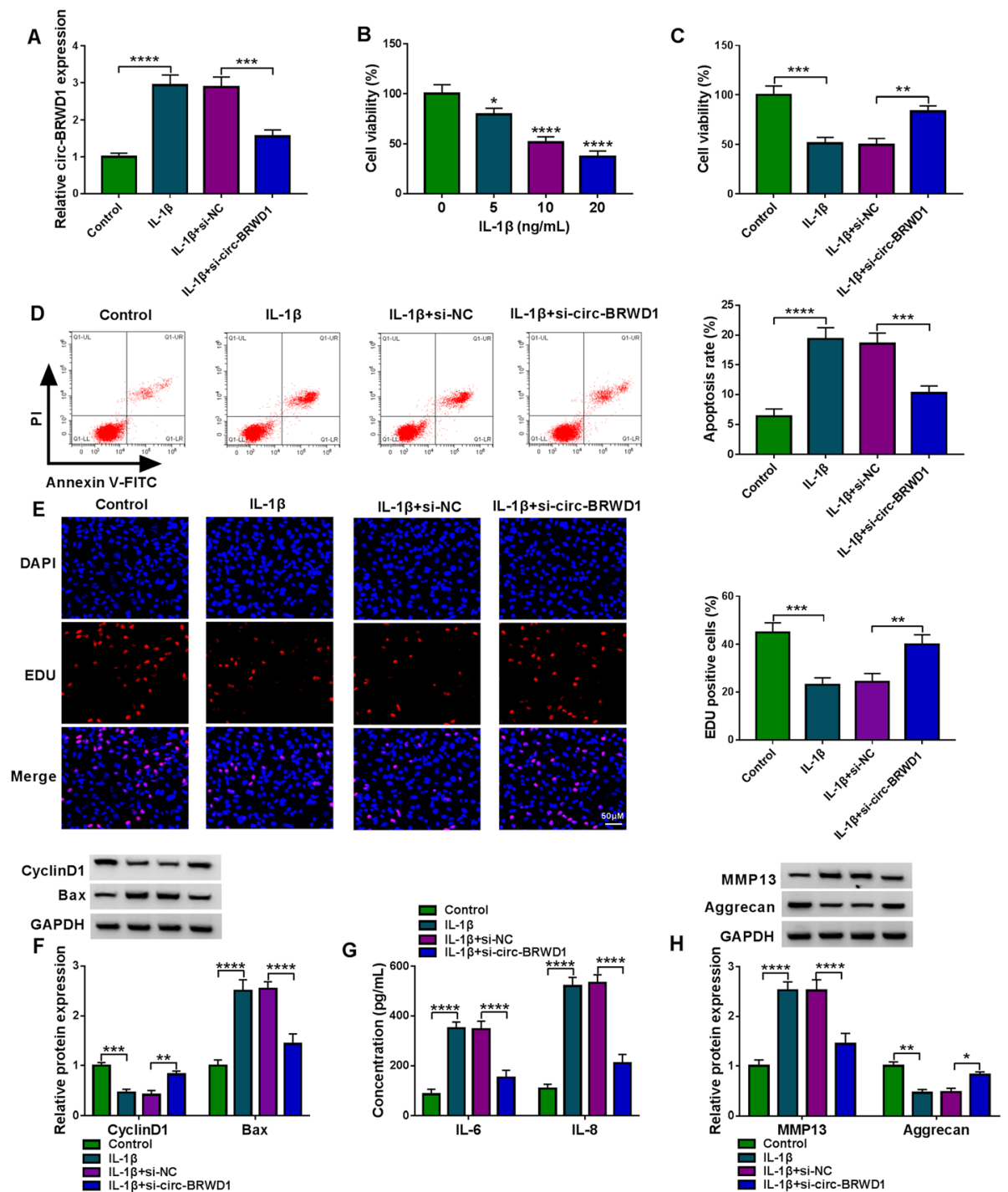

Fig. 3 Knockdown of circ-BRWD1 reversed IL-1 $\beta$-mediated cell viability, apoptosis, inflammation and ECM degradation in CHON-001 cells. A The expression level of circ-BRWD1 in IL-1 $\beta, I L-1 \beta+s i-N C$, or IL-1 $\beta+$ si-circ-BRWD1 treated CHON-001 cells or untreated cells (control) was determined by qRT-PCR assay. $\mathbf{B}$ The viability of CHON-001 cells in different doses of IL-1 $\beta$-treated CHON-001 cells was evaluated by CCK-8 assay. C-F CHON001 cells were assigned to 4 groups: control, IL-1 $\beta, I L-1 \beta+s i-N C$, and IL-1 $\beta+$ si-circ-BRWD1. C, D The viability and apoptosis of CHON-001 cells were analyzed by CCK-8 assay and flow cytometry analysis, respectively. $\mathbf{E}$ The proliferation of CHON-001 cells was assessed by western blot assay. $\mathbf{F}$ The protein levels of CyclinD1 and Bax in CHON-001 cells were measured by western blot assay. G The concentrations of IL-6 and IL-8 in CHON001 cells were examined by ELISA. H The protein levels of MMP13 and aggrecan in CHON-001 cells were measured by western blot assay. The expression of circ-BRWD1 was examined by $2^{-\triangle \Delta \mathrm{Ct}}$ method with normalization to GAPDH. ${ }^{*} P<0.05,{ }^{* *} P<0.01,{ }^{* * *} P<0.001,{ }^{* * * *} P<0.0001$

cells, with miR-1277 inhibition abrogated the effects (Fig. 5F). ELISA data showed that circ-BRWD1 silencing reduced the concentrations of IL- 6 and IL- 8 in IL- $1 \beta$ stimulated $\mathrm{CHON}-001$ cells, whereas these impacts were abolished by decreasing miR-1277 (Fig. 5G). Furthermore, western blot assay showed that MMP13 level was reduced and aggrecan level was elevated in IL-1 $\beta$-treated CHON-001 cells with circ-BRWD1 silencing, while miR1277 suppression ameliorated the effects (Fig. 5H). Taken together, circ-BRWD1 interference relieved IL-
$1 \beta$-induced injury of CHON-001 cells by targeting miR1277.

TRAF6 was a direct target gene of miR-1277

Through analyzing Targetscan software, TRAF6 was found to be a target gene of miR-1277 (Fig. 6A). Then dual-luciferase reporter assay showed that miR-1277 transfection resulted in a remarkable suppression in the luciferase activity of WT-TRAF6 3'UTR in CHON-001 cells, while there was no impact on the luciferase activity 


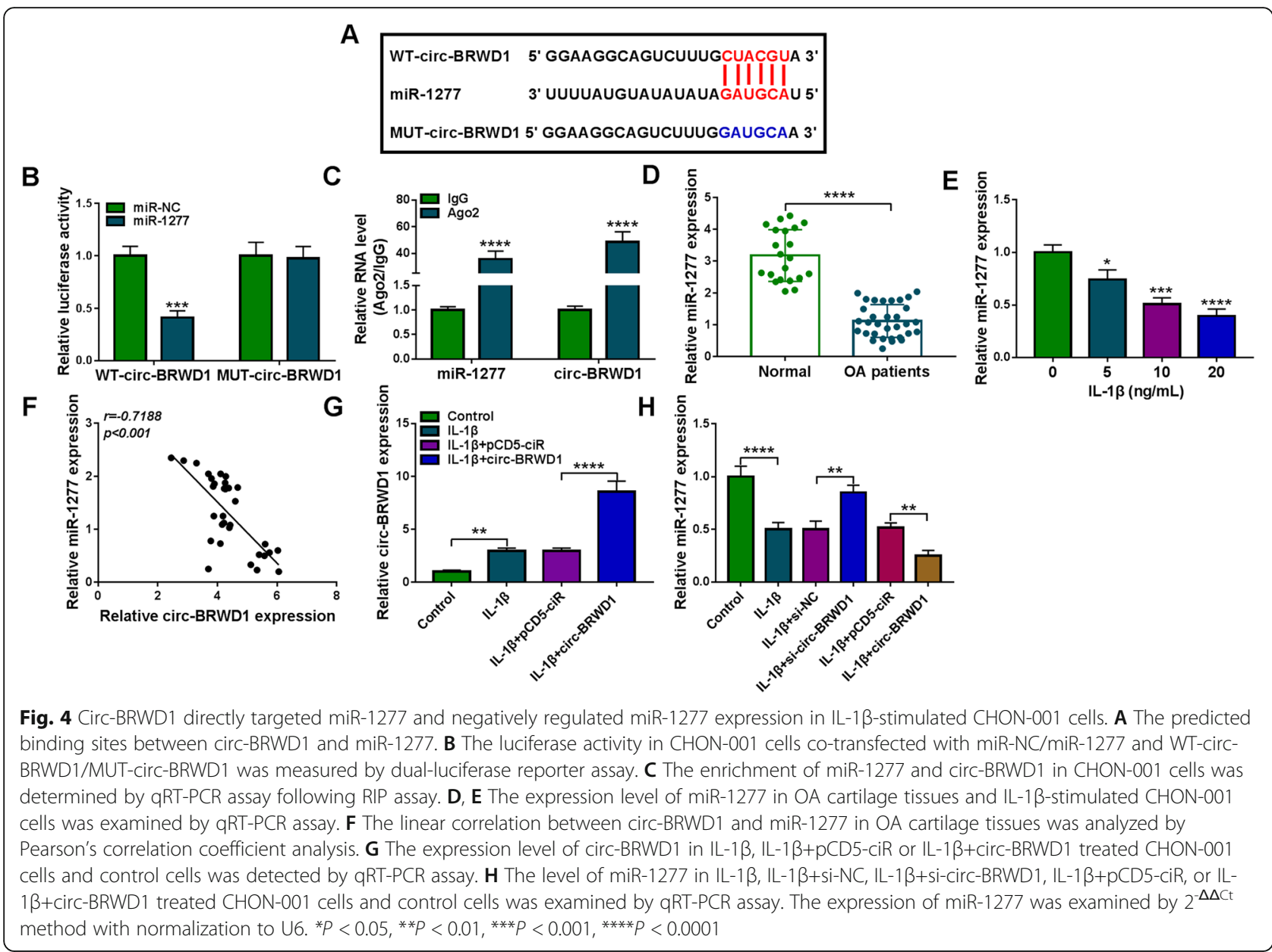

in MUT-TRAF6 3'UTR groups (Fig. 6B). Subsequently, RIP assay was conducted to further determine the combination between miR-1277 and TRAF6. The results showed that miR-1277 and TRAF6 levels were all upregulated in Ago2 immunoprecipitates in comparison with IgG groups (Fig. 6C). As we expected, the mRNA and protein levels of TRAF6 were all conspicuously elevated in OA cartilage tissues compared to normal cartilage tissues (Fig. 6D, E). We also determined the protein level of TRAF6 in IL-1 $\beta$-treated CHON-001 cells, exhibiting that TRAF6 protein level was remarkably raised in IL$1 \beta$-treated CHON-001 cells in a dose-dependent way (Fig. 6F). Furthermore, we observed that TRAF6 level was negatively correlated with miR-1277 level in OA cartilage tissues (Fig. 6G). Additionally, our results showed that miR-1277 transfection led to a marked increase in miR-1277 level and anti-miR-1277 transfection led to a distinct decrease in miR-1277 level in IL-1 $\beta$ treated $\mathrm{CHON}-001$ cells, which indicated the successful transfection of miR-1277 and anti-miR-1277 (Fig. 6H). Western blot assay data showed that miR-1277 overexpression apparently reduced TRAF6 protein level in IL$1 \beta$-treated CHON-001 cells, while miR-1277 suppression exhibited the opposite result in TRAF6 protein level (Fig. 6I). Collectively, miR-1277 negatively regulated TRAF6 expression by direct interaction.

\section{MiR-1277 overexpression promoted cell viability and} inhibited apoptosis, inflammation, and ECM degradation in IL-1 $\beta$-activated $\mathrm{CHON}-001$ cells

To elucidate the association between miR-1277 and TRAF6 in OA development, CHON-001 cells were assigned to 6 groups: control, IL- $1 \beta+\operatorname{miR}-\mathrm{NC}$, IL- $1 \beta+$ miR-1277, IL-1 $\beta+$ miR-1277+pcDNA, and IL- $1 \beta+$ miR1277+TRAF6. As we observed in Fig. 7A, TRAF6 transfection effectively restored the downregulation of TRAF6 protein level mediated by miR-1277 in IL-1 $\beta$-stimulated CHON-001 cells. As illustrated by CCK-8 assay, flow cytometry analysis and EDU assay, miR-1277 overexpression strikingly facilitated cell viability and proliferation and restrained cell apoptosis in IL- $1 \beta$-activated CHON001 cells, while the impacts were rescued by elevating TRAF6 (Fig. 7B-E). Western blot assay showed that miR-1277 overexpression increased CyclinD1 expression and decreased Bax expression in IL- $1 \beta$-treated CHON001 cells, while the impacts were reversed by elevating 
A $\approx$

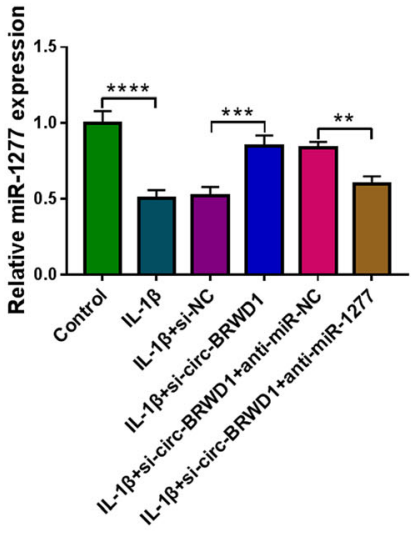

D

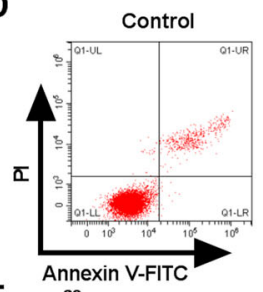

E

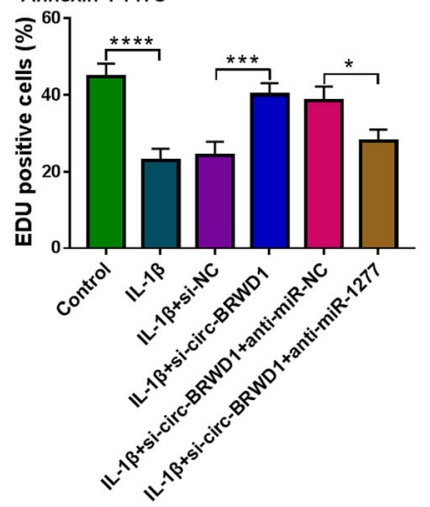

G

$$
\begin{aligned}
& \text { Control } \\
& \text { IL-1 } \beta \\
& \text { IL-1 } \beta+\text { si-NC } \\
& \text { IL-1 } \beta+\text { si-circ-BRWD1 }
\end{aligned}
$$

IL-1 $\beta+$ si-circ-BRWD1+anti-miR-NC

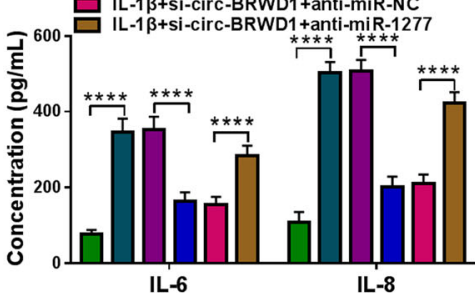

B

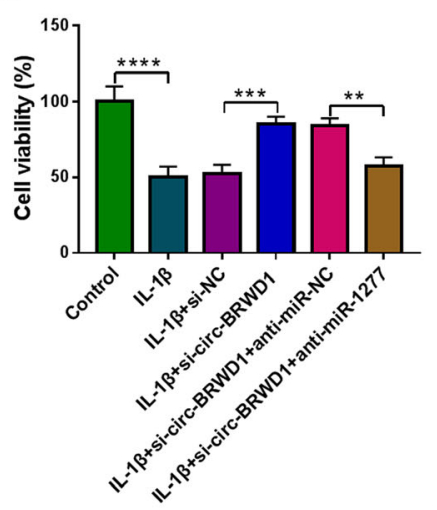

C

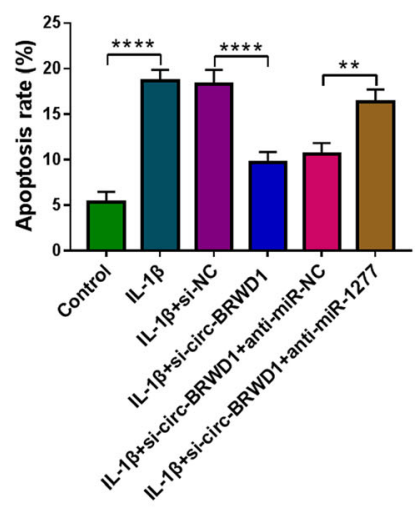

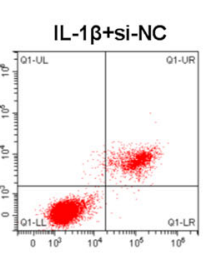

$\mathbf{F}$

IL-1 $\beta+$ si-circ-BRWD1 IL-1 $\beta+$ si-circ-BRWD1
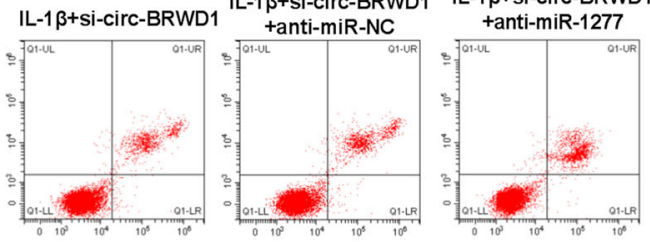

H
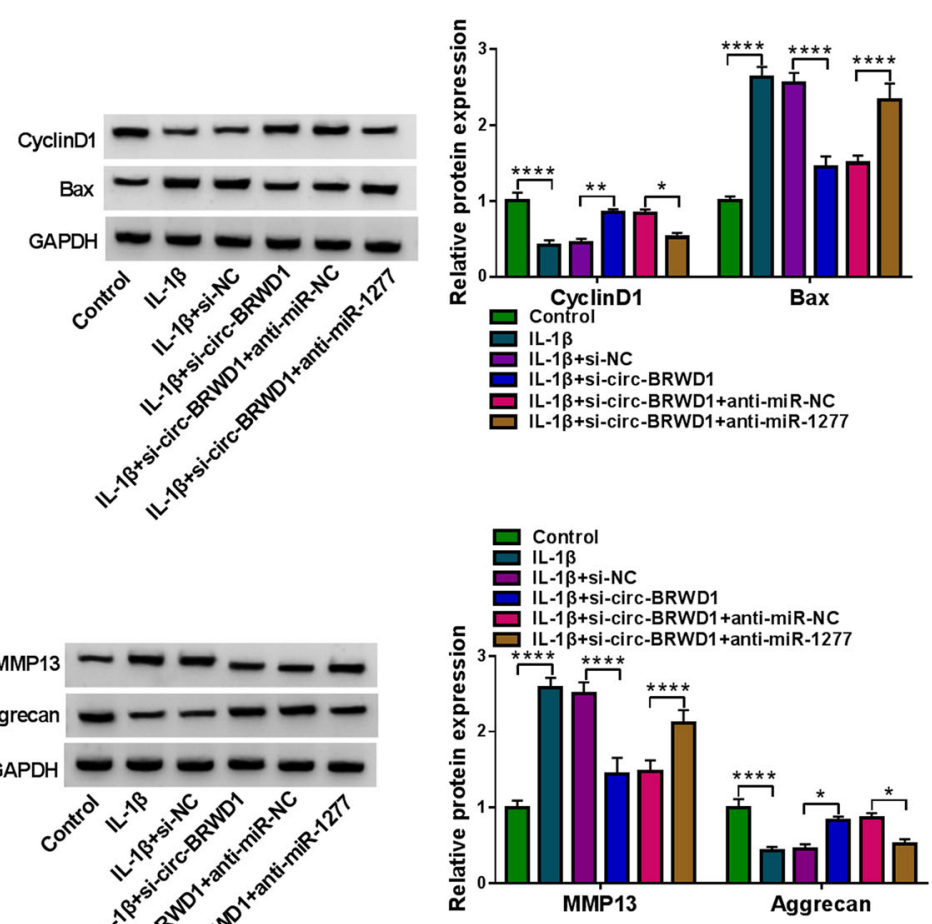

Fig. 5 Circ-BRWD1 silencing promoted cell viability and inhibited apoptosis, inflammation and ECM degradation in IL-1 $\beta$-stimulated CHON-001 cells by binding to miR-1277. CHON-001 cells were assigned to control, IL-1 $\beta$, IL-1 $\beta+$ si-NC, IL-1 $\beta+$ si-circ-BRWD1, IL-1 $\beta+$ si-circ-BRWD1+anti-miR-NC, and IL-1 $\beta+$ si-circ-BRWD1+anti-miR-1277 groups. A QRT-PCR assay was adopted for miR-1277 level in CHON-001 cells. B-D The viability and apoptosis of $\mathrm{CHON}-001$ cells were evaluated by CCK-8 assay and flow cytometry analysis, respectively. $\mathbf{E}$ The proliferation of $\mathrm{CHON}-001$ cells was assessed by EDU assay. $\mathbf{F}$ The protein levels of CyclinD1 and Bax were measured by western blot assay. G ELISA was conducted for the levels of IL-6 and IL-8 in CHON-001 cells. H Western blot assay was carried out for the protein levels of MMP13 and aggrecan in CHON-001 cells. The expression of miR-1277 was examined by $2^{-\triangle \Delta C t}$ method with normalization to U6. ${ }^{*} P<0.05,{ }^{* *} P<0.01,{ }^{* * *} P<0.001,{ }^{* * *} P<0.0001$ 


\section{A TRAF6 3'UTR-WT 5' GUAGUAUUAUAUGUAAUAUAUUA 3' miR-1277 3' UGCaUguaUAUAUA-UAUAUAAa 5. \\ TRAF6 3'UTR-MUT 5' GUAguaUaUaUaguauauauaAa 3'}
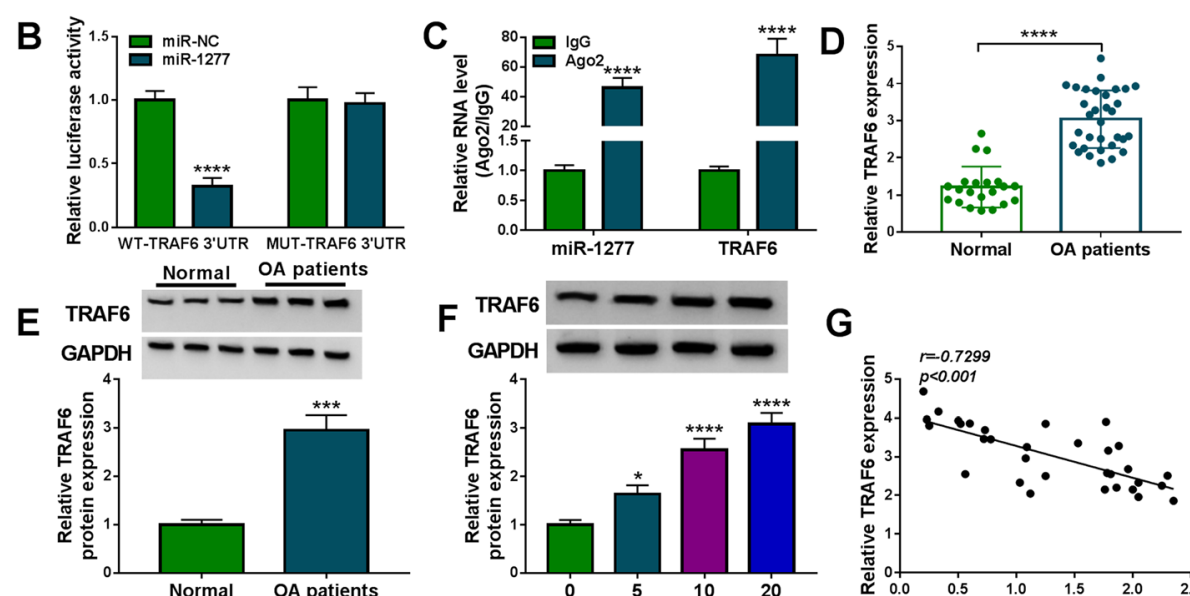

G
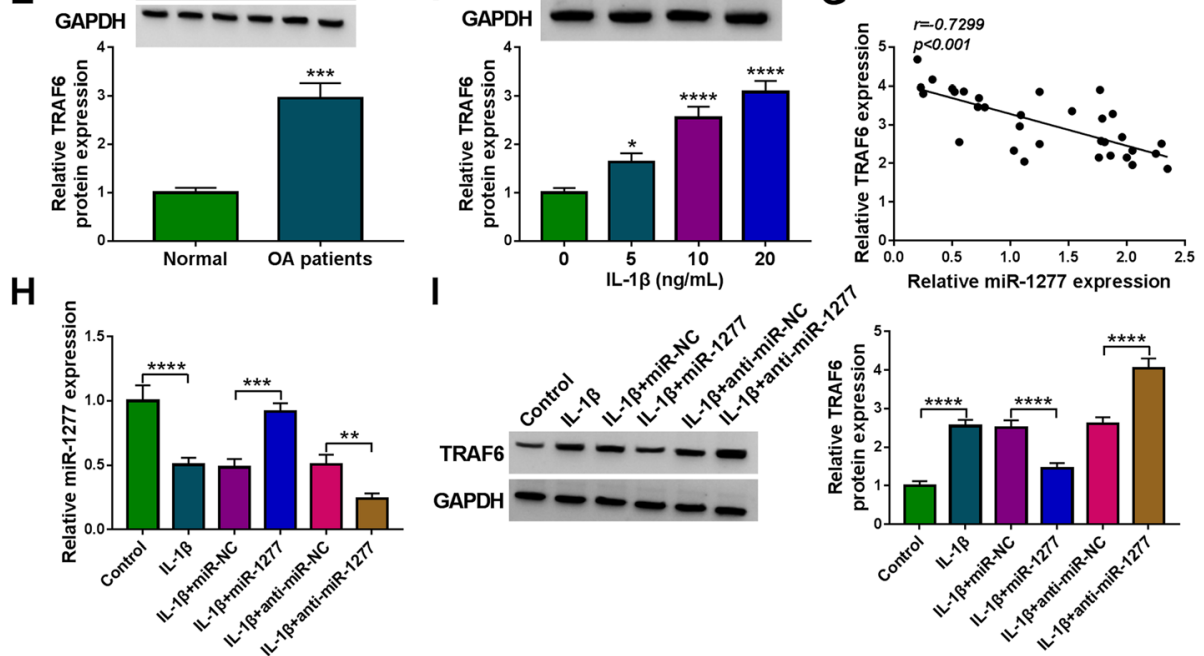

Relative miR-1277 expression

Fig. 6 TRAF6 was directly targeted by miR-1277. A The predicted binding sites between TRAF6 and miR-1277. B, C The interaction between miR1277 and TRAF6 was analyzed by dual-luciferase reporter assay and RIP assay. D, E The mRNA and protein levels of TRAF6 in OA cartilage tissues and normal cartilage tissues were determined by qRT-PCR assay and western blot assay, respectively. $\mathbf{F}$ The protein level of TRAF6 in different concentrations of IL-1 $\beta$-treated CHON-001 cells was measured by western blot assay. G The correlation between miR-1277 and TRAF6 in OA cartilage tissues was evaluated by Pearson's correlation coefficient analysis. $\mathbf{H}$, I The levels of miR-1277 and TRAF6 protein in IL-1 $\beta$, IL-1 $\beta+$ miR-NC, IL-1 $\beta+$ miR-1277, IL-1 $\beta$ +anti-miR-NC, or IL-1 $\beta$ +anti-miR-1277 treated CHON-001 cells or untreated CHON-001 cells were measured by qRT-PCR assay and western blot assay, respectively. TRAF6 mRNA expression and miR-1277 expression were examined by $2^{-\Delta \Delta \mathrm{ct}}$ method with normalization to GAPDH and U6, respectively. ${ }^{*} P<0.05,{ }^{* *} P<0.01,{ }^{* * *} P<0.001,{ }^{* * *} P<0.0001$

TRAF6 (Fig. 7F). ELISA showed that the concentrations of IL-6 and IL-8 in IL-1 $\beta$-treated CHON-001 cells were reduced following the upregulation of miR-1277, while TRAF6 overexpression abolished the impacts (Fig. 7G). In addition, miR-1277 overexpression decreased MMP13 level and increased aggrecan level in IL-1ß-stimulated CHON-001 cells, with TRAF6 elevation reversing the impacts (Fig. $7 \mathrm{H}$ ). All results indicated that miR-1277 overexpression attenuated IL-1 $\beta$-induced injury of CHON-001 cells by targeting TRAF6.

\section{Circ-BRWD1 knockdown reduced TRAF6 expression via sponging miR-1277}

Finally, we further analyzed the relationships among circ-BRWD1, miR-1277 and TRAF6 in IL-1 $\beta$-treated CHON-001 cells. Our results of qRT-PCR assay and western blot assay presented that IL-1 $\beta$ treatment led to marked enhancement in TRAF6 mRNA and protein levels in CHON-001 cells. Moreover, we found that circBRWD1 silencing significantly decreased the mRNA and protein levels of TRAF6 in IL-1 $\beta$-stimulated $\mathrm{CHON}-001$ cells, while miR-1277 suppression ameliorated these impacts (Fig. 8A, B). Taken together, circ-BRWD1 positively modulated TRAF6 expression through functioning as the sponge for miR-1277 in IL- $1 \beta$-stimulated CHON001 cells.

\section{Discussion}

Up to date, numerous circRNAs have been identified to be associated with the progression of human diseases. Nevertheless, the biological roles of circRNAs in $\mathrm{OA}$ are not well known. In the research, we focused on the effects of exosomal circ-BRWD1 in OA pathogenesis. IL-1 $\beta$ was utilized to treat $\mathrm{CHON}-001$ 


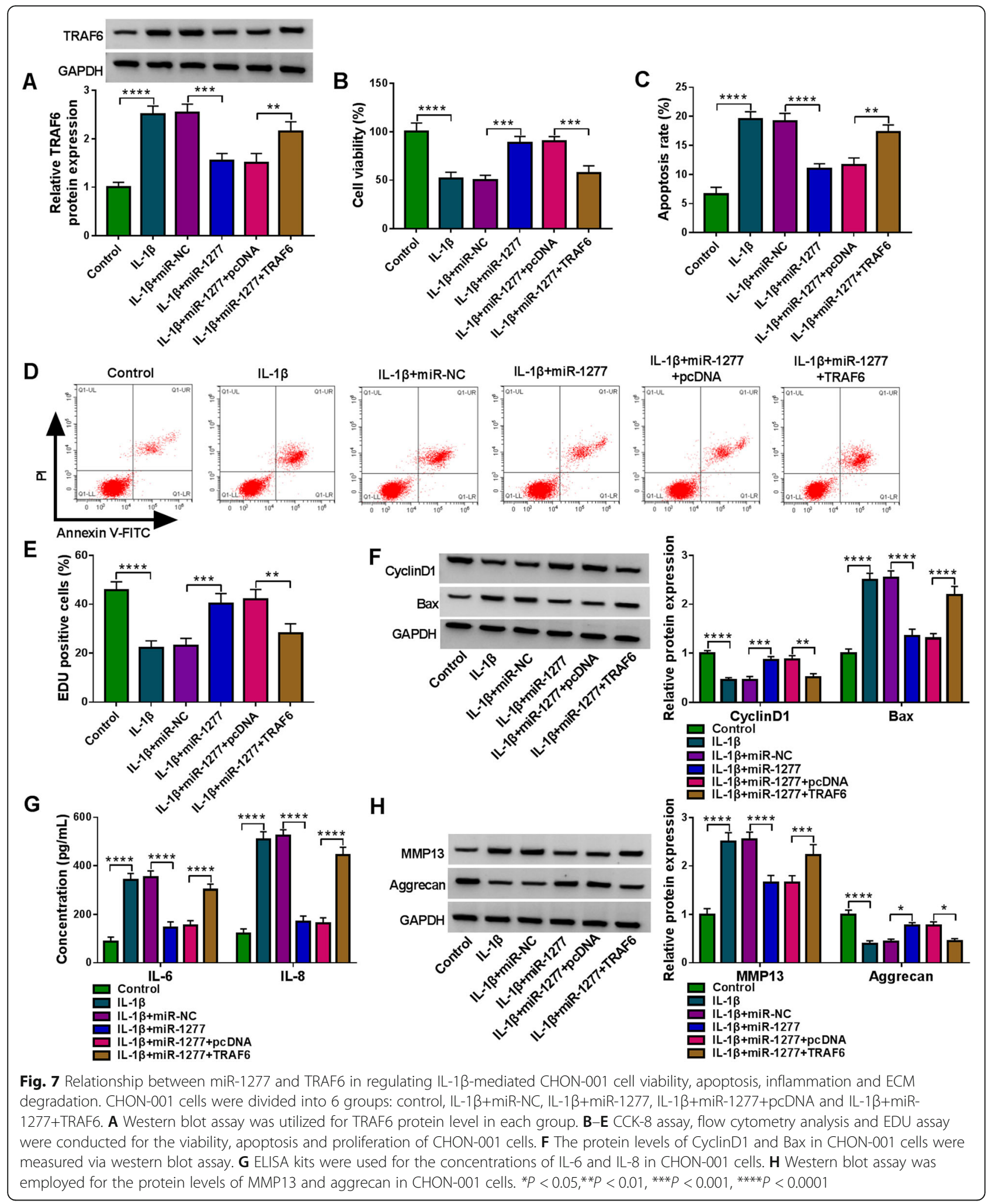

cells to construct an OA model in vitro, as previously mentioned [20, 21]. We found that IL-1 $\beta$ treatment repressed CHON-001 cell viability and induced apoptosis, inflammation and ECM degradation. Moreover, exosomal circ-BRWD1 level was elevated in IL-1 $\beta$-activated CHON-001 cells. Circ-BRWD1 

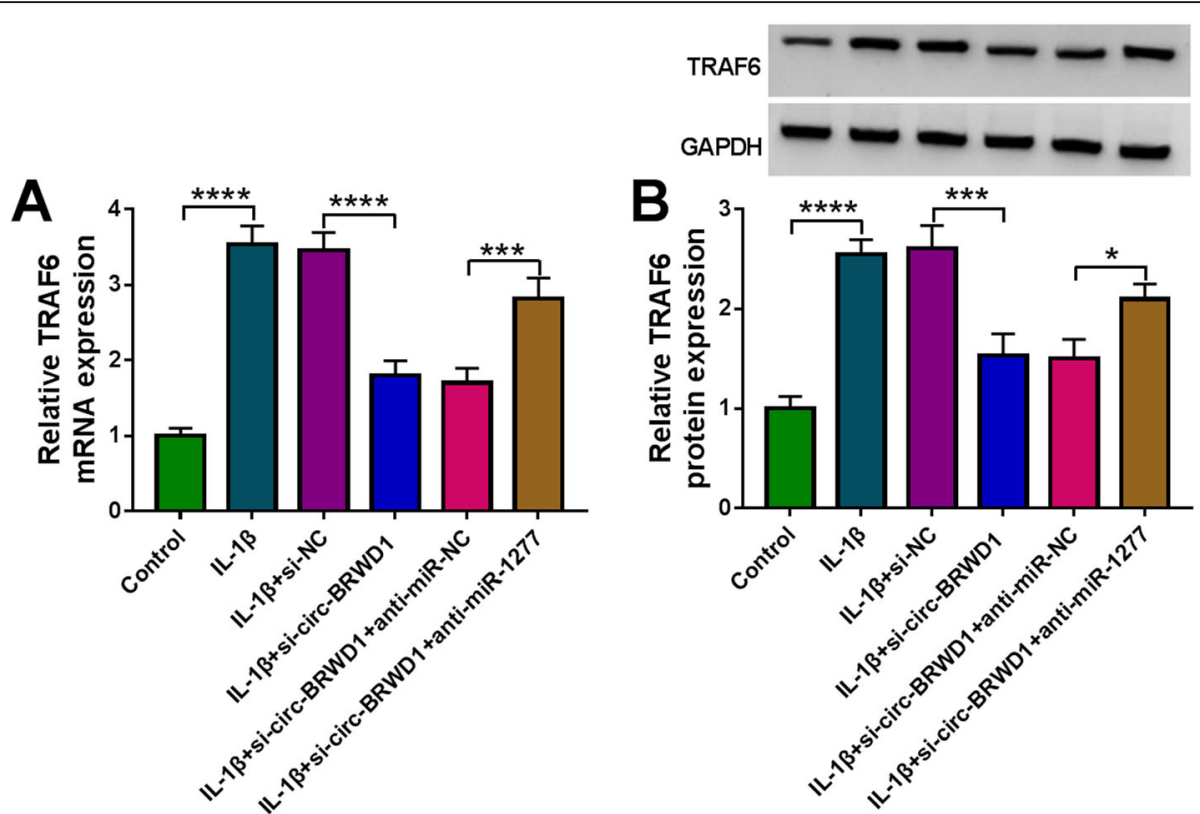

Fig. 8 Circ-BRWD1 positively regulated TRAF8 expression by targeting miR-1277 in IL-1 $\beta$-treated CHON-001 cells. A, B The mRNA and protein

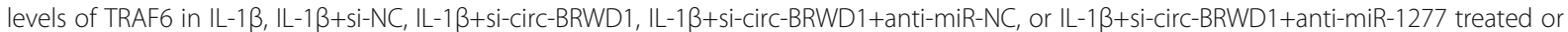
untreated CHON-001 cells were determined by qRT-PCR assay and western blot assay, respectively. TRAF6 mRNA expression was examined by $2^{-\Delta \Delta \mathrm{Ct}}$ method with normalization to GAPDH. ${ }^{*} P<0.05,{ }^{* * *} P<0.001,{ }^{* * *} P<0.0001$

knockdown protected CHON-001 cells from IL-1 $\beta$ activated injury by miR-1277/TRAF6 axis.

The vital roles of exosome-mediated circRNAs have been demonstrated in human illnesses. For instance, exosomal circ_MMP2 accelerated the malignancy of hepatocellular carcinoma by modulating miR-136-5p/ MMP2 axis [22]. Exosome-mediated circ_0044516 contributed to prostate cancer carcinogenesis [23]. Moreover, several circRNAs, such as circ_0045714 [10], circ_0136474 [11] and circGCN1L1 [24], have been reported to play vital roles in OA. Herein, we elucidated the role of exosome-mediated circ-BRWD1 in OA progression. Circ-BRWD1 level was raised in $\mathrm{OA}$ cartilage tissues and IL- $1 \beta$-induced $\mathrm{CHON}-001$ cells. Circ-BRWD1 level was also increased in the exosomes derived from IL-1 $\beta$-stimulated $\mathrm{CHON}-001$ cells. Moreover, exosome treatment elevated circBRWD1 level in IL-1 $\beta$-activated CHON-001 cells, while GW4869 treatment reduced circ-BRWD1 level, indicating exosomes mediated the transmission of circ-BRWD1. Functionally, deficiency of circ-BRWD1 promoted cell viability and impeded cell apoptosis and inflammatory factors release mediated by IL- $1 \beta$ in CHON-001 cells. In addition, we measured the levels of MMP13 and aggrecan, which play crucial roles in cartilage ECM production during OA development $[25,26]$. Our results exhibited that circBRWD1 silencing decreased MMP13 level and increased aggrecan level in IL-1 $\beta$-stimulated $\mathrm{CHON}-001$ cells, indicating ECM degradation was inhibited. Taken together, exosomal circ-BRWD1 knockdown blocked OA development.

Subsequently, the potential mechanisms of circBRWD1 in regulating OA progression were explored. The data indicated that circ-BRWD1 served as the sponge for miR-1277 to positively alter TRAF6 expression. MiR-1277 was found to be decreased in OA tissues and IL- $1 \beta$-stimulated chondrocytes, and its overexpression restrained the degradation of ECM [17]. Consistently, we observed that miR-1277 was weakly expressed in OA cartilage tissues and IL-1 $\beta$-activated CHON-001 cells. Moreover, miR-1277 overexpression promoted cell viability and hampered apoptosis, inflammatory response and ECM degradation in IL- $1 \beta$-activated CHON-001 cells. MiR-1277 suppression alleviated the impacts of circ-BRWD1 deficiency on cell viability, apoptosis, inflammation and ECM degradation in IL-1 $\beta$ activated CHON-001 cells, suggesting that circBRWD1 deficiency blocked OA progression by sponging miR-1277. Additionally, TRAF6 was identified to be the target gene of miR-1277 for the first time, though it could be targeted by multiple miRNAs [27-29]. Of note, we demonstrated that TRAF6 upregulation abrogated the impact of miR-1277 on the progression of IL- $1 \beta$-activated CHON-001 cells, indicating that miR-1277 regulated OA development by targeting TRAF6. 


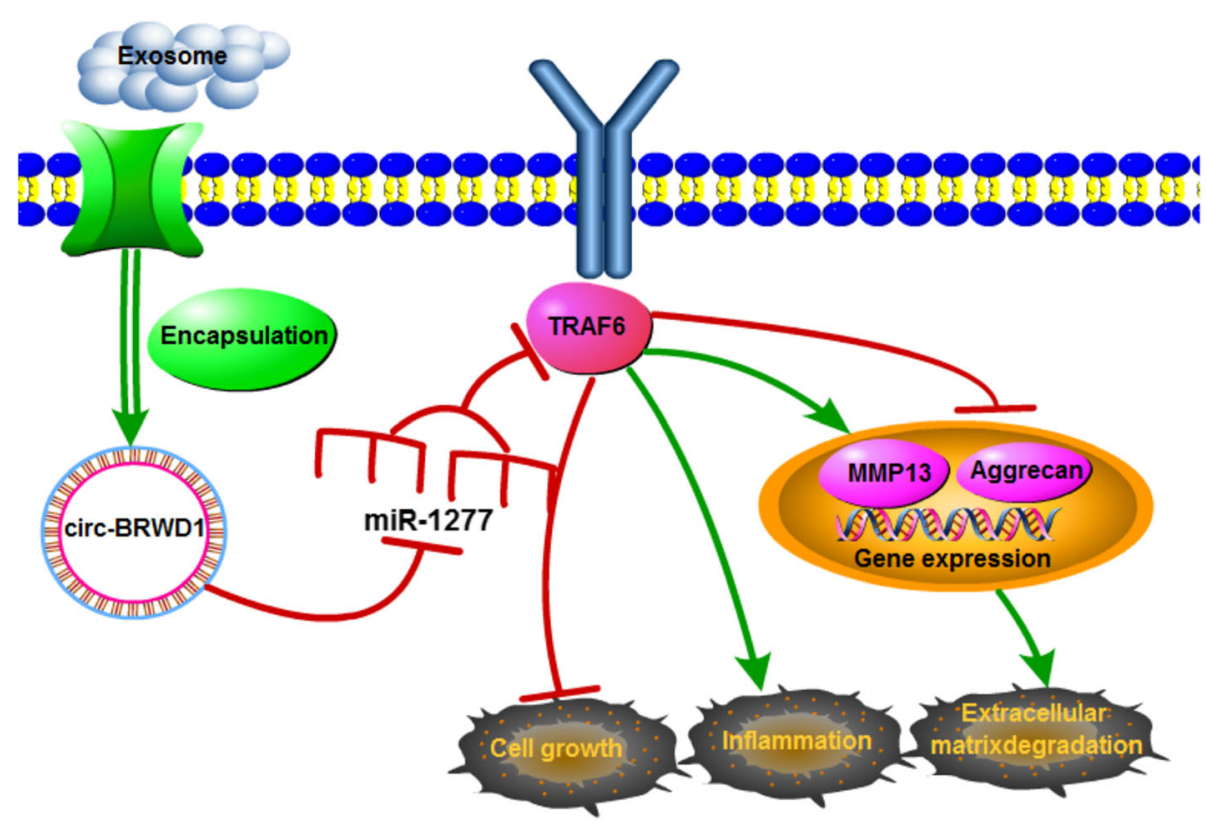

Fig. 9 The schematic diagram of exosomal circ-BRWD1 in regulating chondrocyte growth, inflammation, and ECM degradation

\section{Conclusions}

Exosomal circ-BRWD1 was upregulated in OA cell model and impeded chondrocyte viability and facilitated apoptosis, inflammation and ECM degradation by elevating TRAF6 via sponging miR-1277 (Fig. 9). The research might bring a new sight for OA therapy.

\section{Abbreviations}

OA: Osteoarthritis; CircRNAs: Circular RNAs; BRWD1: Bromodomain and WD repeat domain containing 1 ; IL-1 $\beta$ : Interleukin-1 $\beta$; TRAF6: TNF receptorassociated factor 6; TEM: Transmission electron microscopy; CCK-8: Cell Counting Kit-8; EDU: 5-Ethynyl-2'-deoxyuridine; ELISA: Enzyme-linked immunosorbent assay; IL-6: Interleukin-6; IL-8: Interleukin-8; RIP: RNA immunoprecipitation; ECM: Extracellular matrix; ncRNAs: Non-coding RNAs; miRNAs: MicroRNAs; IGF1R: Insulin-like growth factor 1 receptor; 3'UTR: 3' untranslated region; MMP13: Matrix Metallopeptidase 13; ADAMTS5: ADAM metallopeptidase with thrombospondin type 1 motif 5; ATCC: American Type Culture Collection; DMEM: Dulbecco's modified Eagle's medium; FBS: Fetal bovine serum; qRT-PCR: Quantitative real-time polymerase chain reaction; GAPDH: Glyceraldehyde 3-phosphate dehydrogenase; RIPA: Radio Immunoprecipitation Assay; BCA: Bicinchoninic acid; ECL: Enhanced chemiluminescence; Annexin V-FITC: Annexin V-fluorescein isothiocyanate; PI: Propidium iodide; IgG: Immunoglobulin G; Ago2: Argonaute-2; MMP2: Matrix Metallopeptidase 2

\section{Acknowledgements}

Not applicable

\section{Authors' contributions}

Conceptualization and Methodology: Huan Wang and Feng Zhao; Formal analysis and Data curation: Min Liu, Feida Wang and Mingming Kang; Validation and Investigation: Zhenye Guo, Weifu He and Zhi Lv; Writing original draft preparation and Writing - review and editing: Zhenye Guo, Huan Wang, Feng Zhao and Zhi Lv; Approval of final manuscript: all authors.

\section{Funding}

No funding was received.

\section{Availability of data and materials}

The analyzed data sets generated during the present study are available from the corresponding author on reasonable request.

\section{Declarations}

Ethics approval and consent to participate

The present study was approved by the ethical review committee of the Second Hospital of Shanxi Medical University. Written informed consent was obtained from all enrolled patients.

\section{Consent for publication}

The results presented in this paper have not been published previously in whole or in part.

\section{Competing interests}

The authors declare that they have no competing interests.

\section{Author details}

${ }^{1}$ Department of Orthopaedics, Second Hospital of Shanxi Medical University, No.2 Hospital, Shanxi Medical University, 382 Wuyi Road, Xinghualing District, Taiyuan City, Shanxi Province, China. ${ }^{2}$ Department of Orthopaedics, Shanxi Medical University, West Hospital, Second Hospital, Shanxi Medical University, 379 Yingzhi Street, Wanbai District, Taiyuan City, Shanxi Province, China.

Received: 1 February 2021 Accepted: 21 May 2021

Published online: 03 June 2021

\section{References}

1. van der Kraan PM. Osteoarthritis year 2012 in review: biology. Osteoarthr Cartil. 2012;20(12):1447-50. https://doi.org/10.1016/j.joca.2012.07.010.

2. Glyn-Jones S, Palmer AJ, Agricola R, Price AJ, Vincent TL, Weinans H, et al. Osteoarthritis. Lancet. 2015;386(9991):376-87. https://doi.org/10.1016/S01406736(14)60802-3.

3. Dreier R. Hypertrophic differentiation of chondrocytes in osteoarthritis: the developmental aspect of degenerative joint disorders. Arthritis Res Ther. 2010;12(5):216. https://doi.org/10.1186/ar3117.

4. Rahmati M, Nalesso G, Mobasheri A, Mozafari M. Aging and osteoarthritis: central role of the extracellular matrix. Ageing Res Rev. 2017;40:20-30.

5. Honvo G, Reginster JY, Rabenda V, Geerinck A, Mkinsi O, Charles A, et al. Safety of symptomatic slow-acting drugs for osteoarthritis: outcomes of a 
systematic review and meta-analysis. Drugs Aging. 2019;36(Suppl 1):65-99. https://doi.org/10.1007/s40266-019-00662-z.

6. Mathiessen A, Conaghan PG. Synovitis in osteoarthritis: current understanding with therapeutic implications. Arthritis Res Ther. 2017;19(1): 18. https://doi.org/10.1186/s13075-017-1229-9.

7. Patop IL, Kadener S. circRNAs in cancer. Curr Opin Genet Dev. 2018;48:1217.

8. Zhou R, Wu Y, Wang W, Su W, Liu Y, Wang Y, et al. Circular RNAs (circRNAs) in cancer. Cancer Lett. 2018;425:134-42.

9. Wu Y, Zhang Y, Zhang Y, Wang JJ. CircRNA hsa_circ_0005105 upregulates NAMPT expression and promotes chondrocyte extracellular matrix degradation by sponging miR-26a. Cell Biol Int. 2017;41(12):1283-9. https:// doi.org/10.1002/cbin.10761

10. Li BF, Zhang Y, Xiao J, Wang F, Li M, Guo XZ, et al. Hsa_circ_0045714 regulates chondrocyte proliferation, apoptosis and extracellular matrix synthesis by promoting the expression of miR-193b target gene IGF1R. Hum Cell. 2017;30(4):311-8. https://doi.org/10.1007/s13577-017-0177-7.

11. Li Z, Yuan B, Pei Z, Zhang K, Ding Z, Zhu S, et al. Circ_0136474 and MMP-13 suppressed cell proliferation by competitive binding to miR-127-5p in osteoarthritis. J Cell Mol Med. 2019;23(10):6554-64. https://doi.org/10.1111/ jcmm.14400.

12. Sun Z, Shi K, Yang S, Liu J, Zhou Q, Wang G, et al. Effect of exosomal miRNA on cancer biology and clinical applications. Mol Cancer. 2018;17(1):147. https://doi.org/10.1186/s12943-018-0897-7.

13. Kahlert C, Kalluri R. Exosomes in tumor microenvironment influence cancer progression and metastasis. J Mol Med (Berl). 2013;91(4):431-7. https://doi. org/10.1007/s00109-013-1020-6.

14. Nana-Sinkam SP, Croce CM. MicroRNA regulation of tumorigenesis, cancer progression and interpatient heterogeneity: towards clinical use. Genome Biol. 2014;15(9):445. https://doi.org/10.1186/s13059-014-0445-8.

15. Yan S, Wang M, Zhao J, Zhang H, Zhou C, Jin L, et al. MicroRNA-34a affects chondrocyte apoptosis and proliferation by targeting the SIRT1/p53 signaling pathway during the pathogenesis of osteoarthritis. Int J Mol Med. 2016:38(1):201-9. https://doi.org/10.3892/ijmm.2016.2618.

16. Dai L, Zhang X, Hu X, Zhou C, Ao Y. Silencing of microRNA-101 prevents IL1 beta-induced extracellular matrix degradation in chondrocytes. Arthritis Res Ther. 2012;14(6):R268. https://doi.org/10.1186/ar4114.

17. Wang $T$, Liu $Y$, Wang $Y$, Huang $X$, Zhao W, Zhao Z. Long non-coding RNA XIST promotes extracellular matrix degradation by functioning as a competing endogenous RNA of miR-1277-5p in osteoarthritis. Int J Mol Med. 2019:44(2):630-42. https://doi.org/10.3892/ijmm.2019.4240.

18. West C, McDermott MF. Effects of microRNA-146a on the proliferation and apoptosis of human osteochondrocytes by targeting TRAF6 through the NF- kappaB signalling pathway. Biosci Rep. 2017;37(4):BSR20170180.

19. Jung MK, Mun JY. Sample preparation and imaging of exosomes by transmission electron microscopy. J Vis Exp. 2018;131:56482.

20. Zeng L, Wang W, Rong X-F, Zhong Y, Jia P, Zhou G-Q, et al. Chondroprotective effects and multi-target mechanisms of Icariin in IL-1 beta-induced human SW 1353 chondrosarcoma cells and a rat osteoarthritis model. Int Immunopharmacol. 2014;18(1):175-81. https://doi.org/10.1016/j. intimp.2013.11.021

21. Daheshia M, Yao JQ. The interleukin 1 beta pathway in the pathogenesis of osteoarthritis. J Rheumatol. 2008;35(12):2306-12. https://doi.org/10.3899/ jrheum.080346.

22. Liu D, Kang H, Gao M, Jin L, Zhang F, Chen D, et al. Exosome-transmitted circ_MMP2 promotes hepatocellular carcinoma metastasis by upregulating MMP2. Mol Oncol. 2020;14(6):1365-80. https://doi.org/10.1002/1878-0261.12 637.

23. Li T, Sun X, Chen L. Exosome circ 0044516 promotes prostate cancer cell proliferation and metastasis as a potential biomarker. J Cell Biochem. 2020; 121(3):2118-26.

24. Zhu H, Hu Y, Wang C, Zhang $X$, He D. CircGCN1L1 promotes synoviocyte proliferation and chondrocyte apoptosis by targeting miR-330-3p and TNFalpha in TMJ osteoarthritis. Cell Death Dis. 2020;11(4):284. https://doi.org/1 0.1038/s41419-020-2447-7.

25. Sofat N. Analysing the role of endogenous matrix molecules in the development of osteoarthritis. Int J Exp Pathol. 2009;90(5):463-79. https:// doi.org/10.1111/j.1365-2613.2009.00676.x.

26. Nagase $H$, Kashiwagi M. Aggrecanases and cartilage matrix degradation. Arthritis Res Ther. 2003:5(2):94-103. https://doi.org/10.1186/ar630.
27. Huang S, Wa Q, Pan J, Peng X, Ren D, Huang Y, et al. Downregulation of miR-141-3p promotes bone metastasis via activating NF-kappaB signaling in prostate cancer. J Exp Clin Cancer Res. 2017;36(1):173. https://doi.org/10.11 86/s13046-017-0645-7.

28. Rosenberger CM, Podyminogin RL, Diercks AH, Treuting PM, Peschon JJ, Rodriguez D, et al. miR-144 attenuates the host response to influenza virus by targeting the TRAF6-IRF7 signaling axis. PLoS Pathog. 2017;13(4): e1006305.

29. He Q, Qiu J, Dai M, Fang Q, Sun X, Gong Y, et al. MicroRNA-351 inhibits denervation-induced muscle atrophy by targeting TRAF6. Exp Ther Med. 2016;12(6):4029-34. https://doi.org/10.3892/etm.2016.3856.

\section{Publisher's Note}

Springer Nature remains neutral with regard to jurisdictional claims in published maps and institutional affiliations.
Ready to submit your research? Choose BMC and benefit from:

- fast, convenient online submission

- thorough peer review by experienced researchers in your field

- rapid publication on acceptance

- support for research data, including large and complex data types

- gold Open Access which fosters wider collaboration and increased citations

- maximum visibility for your research: over $100 \mathrm{M}$ website views per year

At BMC, research is always in progress.

Learn more biomedcentral.com/submissions 